\title{
A REVIEW ON DESIGN OF COMPONENTS OF 4 STROKE ENGINE USING HYBRID METAL MATRIX
}

\author{
V AMIT M NAIDU ${ }^{1}$, S D SHELARE ${ }^{2} \&$ S M AWATADE ${ }^{3}$ \\ ${ }^{1}$ P.G. Scholar, Department of Mechanical Engineering, RTMNU, Nagpur, Maharashtra - 440033 \\ ${ }^{1,2,3}$ Priyadarshini College of Engineering, Nagpur, Maharashtra - 440019
}

\begin{abstract}
In the present study of Aluminum Metal Matrix Composites (AMMCs), specifically speaking, in our case Al-SiC-graphite have been discussed on the basis of literature review, comprising of similar characteristics of base aluminum alloy but not completely identical. Aluminum metal matrix composites have different properties when compared with Cast Iron and Aluminum. This difference in properties gives us a chance to design components which may give better results than the conventional ones. In a new approach, we are trying to develop new components for 4 Stroke Petrol Engine namely piston \& connecting rod, which would have better Tensile Strength, Young's Modulus \& Low Thermal Conductivity as compared to the pure Aluminum.

KEYWORDS: Metal Matrix, Al-SiC-Graphite Specimen, Melting Metallurgy
\end{abstract}

Received: Jun 06, 2020; Accepted: Jun 26, 2020; Published: Aug 21, 2020; Paper Id.: IJMPERDJUN2020842

\section{INTRODUCTION}

What we have learned from our past is that due to our need the solid materials are being replaced by composite materials so as to fullfill our need for obtaining a light weight, elite, nature friendly and corrosion resistance materials [2]. The production and regular improvisation of a variety of Aluminium based composition and use of hybrid metal matrix has been an area of influence in the field of material sciences and engineering for as long as three decades [3-5]. This has been only possible because composites made out of Aluminum shows versatility which has been a success in the field of development of better perfoming components than the conventional ones for defence, marine, automobile, aerospace and far more industrial based application processes including facilities for sports and recreation[6-7]. Metal composite materials have discovered application in numerous zones of day by day life for a long while. Regularly it isn't understood that the application utilizes composite materials. Delivering of such materials is done from regular generation and handling of metals. Combination of metal, ceramic and non metal provides limitless variation [8]. AMC's i.e. Aluminium based metal matrix composite has so many attractive properties that it has gained enormous importance in the field of aerospace and automotive industries. The need for obtaining a material with such optimal density, abrasive resistant properties and specific stiffnes has been fullfilled by the use of these AMC's. Many reports that has been published associates themselves with the development of microstructure and distribution of particles in the matrix alongwith mentioning their mechanical behaviour. At present their are three methods to produce these reinforced composites namely spray depostion techniques, powder metallurgy, and stir casting [9-11].The basis behind this methodology is to obtain a Hybrid Composites made up of specific metal matrices which are engineered by amalgamating different substances so that we get a final product consisting of mixture of advantages of those primary materials.By combining in such a method provides one with a 
number of possible ways for designing a material [12-14]. In a nut shell reinforcement should consist a hard material because it assists in improvement of such desirable properties such as tensile strength and hardness which plays an important role where there is interaction of surfaces in relative motion as in bearings or gears[15].

In this paper an attempt has been made for introduction of AMMCs for manufacturing components of an IC Engine and to achieve better performance characteristics in terms of properties such as Young's Modulus, Poison's Ratio, Impact Strength, Thermal Conductivity etc., also to reduce the overall cost of production of components as compared to their life span.

\section{PROCESSINGMETHDOLOGY}

Various procedures can be employed in creation of metal matirx composite materials. What makes a procedure appropriate is determination of use, application and the necessary properties needed in that final product. The maufacturing technique can be tweaked so as to acquire diverse profiles, eventhough similar techniques and segments are included in both. The creation of an appropriate antecedent material, the handling of a unit under develpoment or a partially completedproduct (profile) and the treatment given for finishing must be isolated.

Following are engineering techniques which can be applied to obtain the final product:

\section{Melting Metallurgical Processes}

- Using squeeze casting or pressure inflitration technique to infiltrate short fiber-, particle- or hybrid performs [16, 17-19]

- Infiltration of fiber- or particle preforms with the help of a reaction [20, 21]

- Processing of precursor material by stirring the particles in metallic melts, followed by sand casting, permanent mould casting or high pressure die casting [22, 23]

\section{Powder Metallurgical Processes}

- Powder mixtures and composite powders being pressed and sintered and/or forged

- Metal-powder particle mixtures being extrude or forged [24, 25]

- Extrusion or forging of spraying compatible precursor materials [16, 26, 27]

- Hot iso-static pressing of powder mixtures and fiber clutches.

- Further processing of precursor material from the melting metallurgy by thixo-casting or -forming, extrusion [28], forging, cold massive forming or super plastic forming.

- Semi-manufactured products being joined and welded.

- Using techniques applied by machines for finishing [29]

- Deforming the combination of metal wires (group superconductors).

The 1st set of procedures is at present more suitable for generation of a composite of metal matrix of more prominent specialized significance than powder metallurgy. It is increasingly prudent and has the upside of having the capacity to utilize well demonstrated forms for creating of metal matrix composites. Figure 1.1 depicts the conceivable 
strategies for softening metallurgical creation. Preparation of composites can be done by utilizing any of the following three systems [19]:

- $\quad$ Melt stirring or Compo-casting.

- Gas pressure infiltration.

- $\quad$ Pressure casting or Squeeze casting.

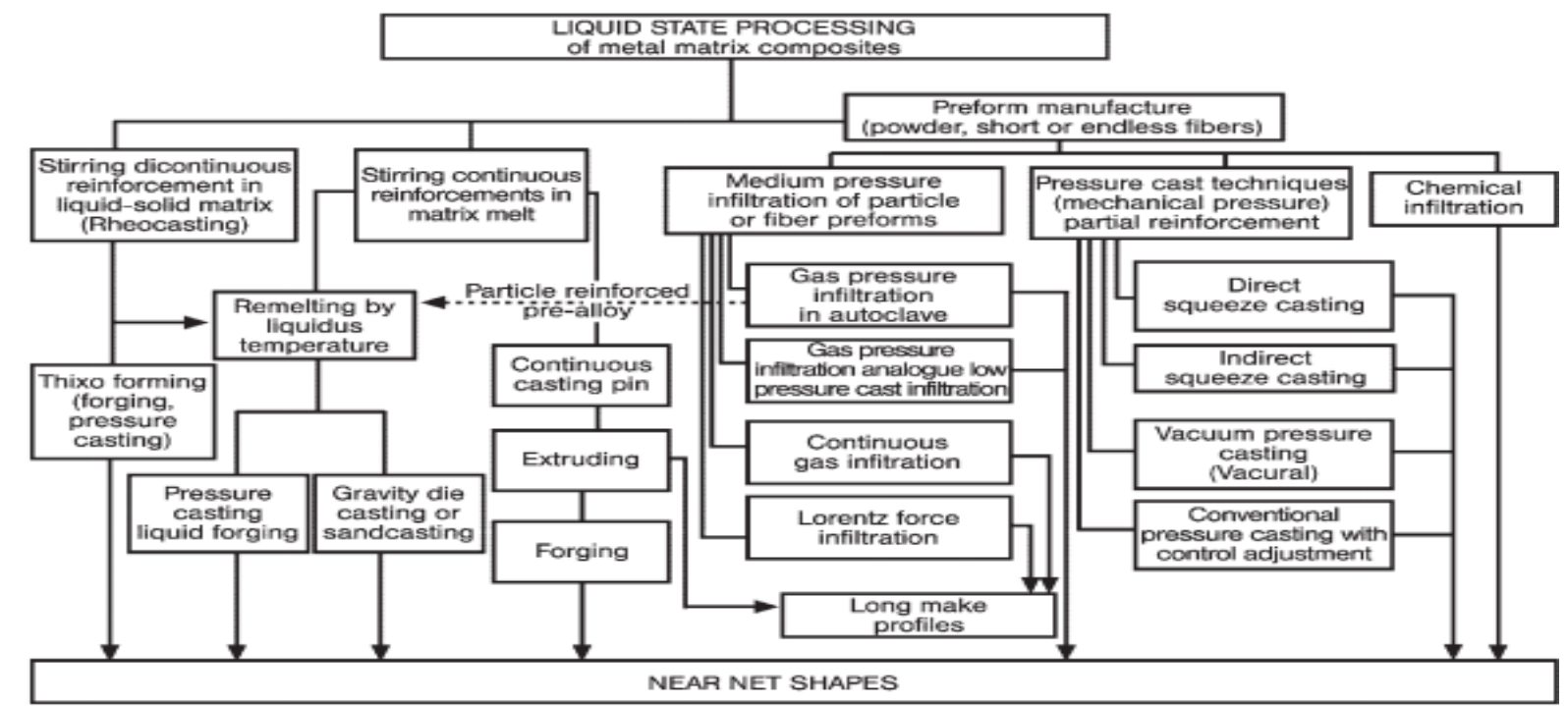

Figure 1.1: Melting Metallurgy of MMCs.

The 1st method consists of using a stirrer to stir the particles in a melt of light alloy. Figure 1.2 depicts how the above mentioned procedure can be conducted schematically.

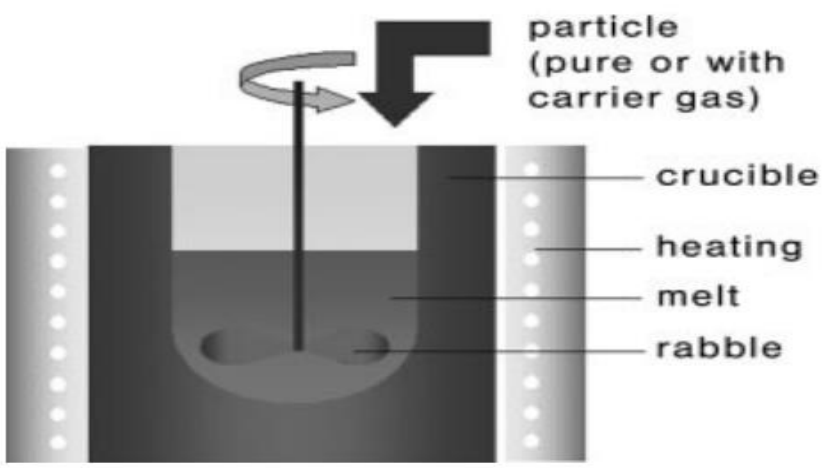

Figure 1.2: Procedure of Melt Stirring using Schematic Operation.

Melt penetrates into the perform in the presence of gas in gas pressure infiltration technique. A gas that is inactive as for the network is utilized. Reasonable pressure vessel is used for the penetration and liqueficattion of the lattice. Gas pressure inversion can be perfomed by using any of the following two methods: The first one consists of a method in which the plunging of heated up preform is done inside the melt and after a connection of gas pressure is given from the outside, prompting penetration into the melt. Wettability of the performs facilitates the penetration pressure depending, on the volume level of fortification. The procedure is reversed in the second method of gas pressure penetration. Squeezing of liquid shower is done in perform with the help of connected gas pressureusing a standpipe which immediately invades the 
bath (see Fig. 1.3). The positive side of applying this technique is, no further advancement of porse takes place when parts having higher density are used. Further more receptive materials can be utilized as this methodology consists of moderate response time for example with the compo-casting.Choosing and facilitation of material must be done wiselysince reaction timeis obviously longer in gas pressure penetration than in squeeze casting, so that they may deliver a desired material which is composite in nature having suitable properties.

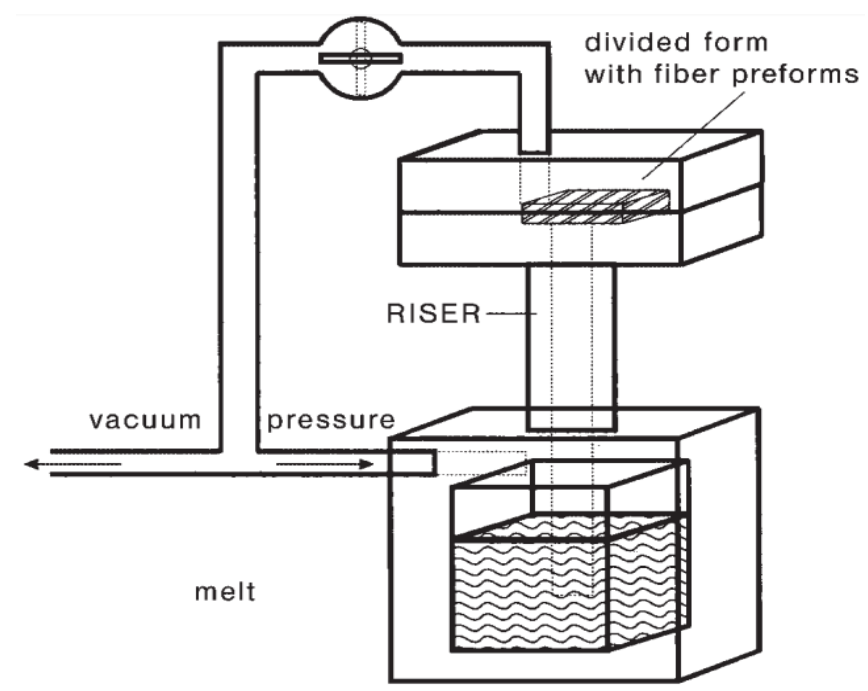

Figure 1.3: Gas Pressure Infiltration Technique.

The most widely used technique for casting of variations for composites of metal matrix is Pressure Casting or Squeeze casting. The melt cements and forms a fine-grained structure under exceptionally high pressure. Thermal treatment is possile for parts of delivery in squeeze casted ones as compared to with those that are die casted as they don't posses gas consideration. The difference in between the two casting methods can be easily spotted (Fig. 1.4). The pressure for the infiltration of pre-assembled performs is connected directly to the melt in the case of direct casting. This techinque helps in improving the structure of tools considerably since the die is thereby part of the mould. Nonetheless, a drawback is noticed inimmediate methodology that is the quantity of dissolve plays a crucial role for determing the unit's cast size which further depends on the factor that how pricisely the melt volume is resolved, since gate is absent here. Again due to the fact that there are oxidating items that are created amid measurements is another drawback. Interestingly, in indirect squeezing,squeezing of the melt in the structure is done by using a grid matrix, thereby residuals is deposited outside this gate. The large diameter of the gate provides a stream rate to the melt which is significantly less than die casting, resulting in a less violent gas admission and form filling to the dissolve and turbulences is maintained within a limit. Composite materials can be obtained by performing any of the two pressure casting processes since both help in the penetration of prefabricated molecule into the melt which under pressure gets cemented. Generally a two step process is used. First step consists of squeezing the melt in structure by applying less pressure amd after that for cementing stage greater pressure is applied.Since inflitration is not quick any harm to the preform is averted.Pressure casting grants utilization of moderately receptive substances, since time of penetration and alongwith it the time of reaction, are generally short. The possibility of fabricating units which are intricate and partially reinforced are easily favourable in such conditions so as to fortify regions presented to a greater stress amid their service life. 

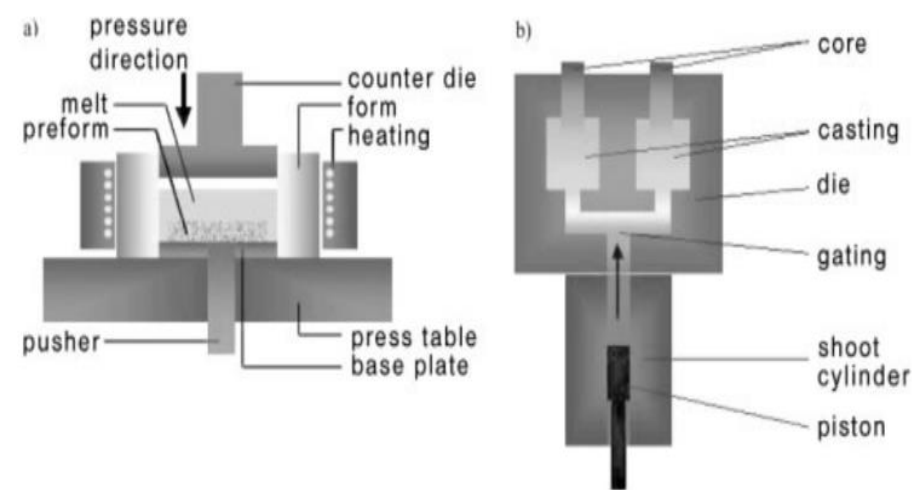

Figure 1.4: Direct and Indirect Squeeze Casting.

\section{PREPARATION OF AL-SIC-GRAPHITE SPECIMEN}

Mix Casting strategy is a technique for creating products, having a dissipated stage (terminated substances, small fibers) is dissolved in a fluid metal by technique of mechanical blending with assistance of stirrer. The fluid state composite material is thrown by lasting bite the dust throwing technique. In this Stir throwing procedure has been utilized to set up the workpiece tests of Al-Sic-Graphite cross breed metal grid Composite material and achieve the required properties of that composite material. The vortex blend throwing is best way to deal with make an exact blending of the silicon carbide and graphite material in the network, the aluminum material was stacked in a cauldron and it was put into an obstruction heater at different temperature levels [30].

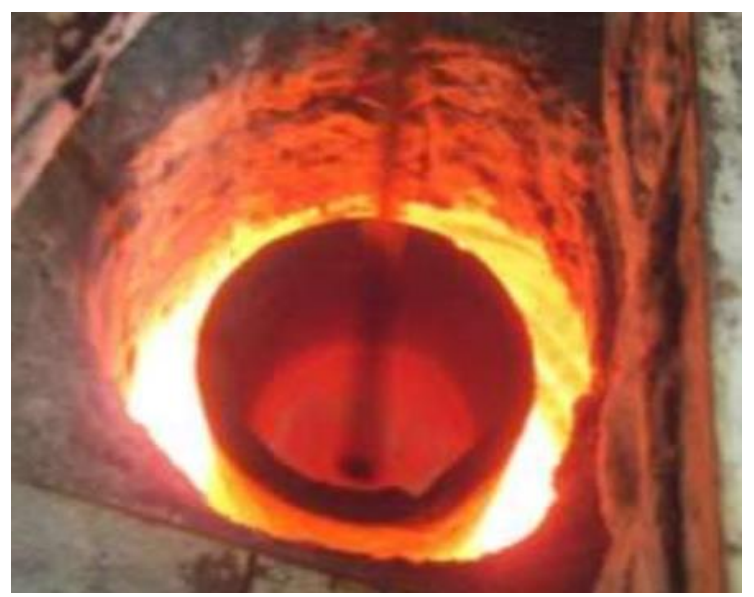

Figure 1.5: Furnace.

Silicon carbide and Graphite powder preheated before blending of aluminum metal mould, the four edged stirrer was planned so as to create the adequate homogenous molecule dissemination all through the grid material [31]. In the wake of getting the homogeneous blending of silicon carbide, graphite powder and aluminum composite liquid metal was filled into permanent die. In casting process die is loaded up with a greasing material for reducing sticking of the casting metal to the die. The vent gaps are provided with the casting for escaping hot gas from the mold. The casting was removed from the die; the casting will be excessively hot, so it must be cooled so as to decrease the oxidation process. The casting material is cooled by the water quenching process. This procedure contains the fast cooling of the casting material by treating with the water. The casting is dunked in to a water to reduce the warmth and to get a solid form of the composite specimen. 


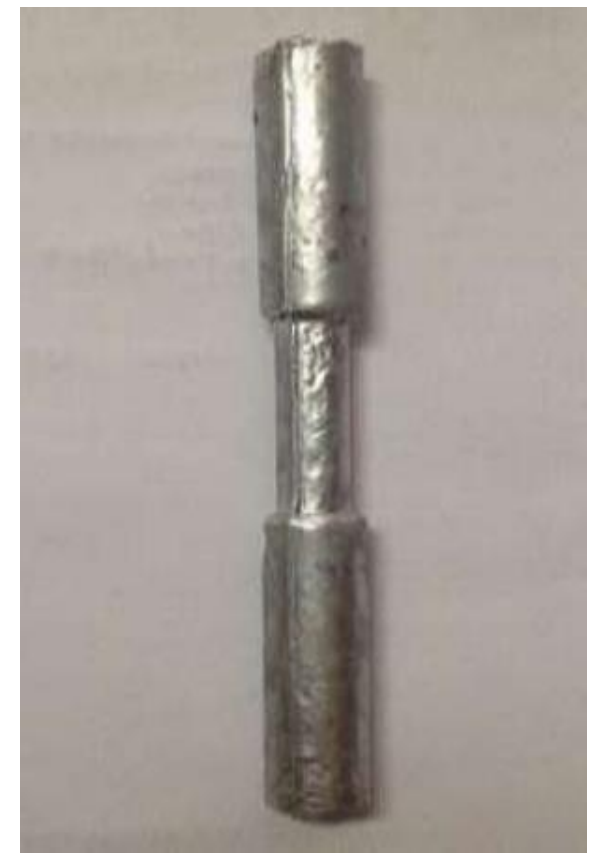

Figure 1.6: Specimen of Al-Sic-Graphite.

\section{TESTING OF AL-SIC-GRAPHITE SPECIMEN}

Following tests are performed:

- $\quad$ Tensile Test

- Brunel Hardness Test

- Impact Test

- Microstructure Analysis

After comparison of the test results with conventional materials, the hardness of cross over metal lattice was enhanced to a greater extent. The surface of Al-Sic-Graphite is shown with help of optical microscope and getting the micro structure of graphite present in hybrid metal matrix.

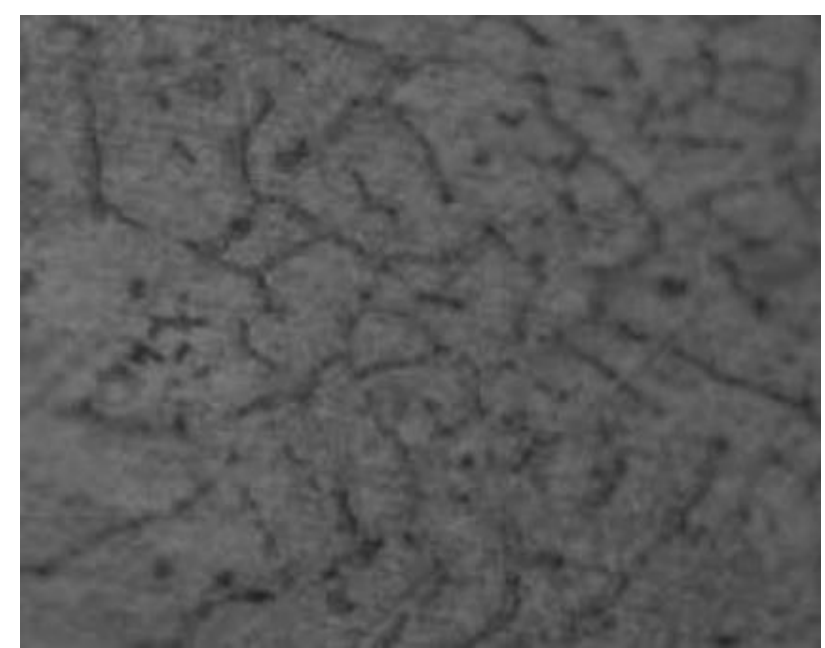

Figure 1.7: Microstructure of Al-SiC-Graphite. 
Following results were obtained:

Table 1.1: Material Parameters of Aluminum (Pure)

\begin{tabular}{|l|c|}
\hline Young's Modulus & $7 \mathrm{e}+10 \mathrm{~Pa}$ \\
\hline Poisson's Ratio & 0.35 \\
\hline Density & $2700 \mathrm{Kg} / \mathrm{m} 3$ \\
\hline Tensile strength & $121.1 \mathrm{MPa}$ \\
\hline Percentage of elongation & $10-15$ \\
\hline BHN & $60-65$ \\
\hline Thermal Conductivity & $237 \mathrm{~W} / \mathrm{m} \mathrm{0C}$ \\
\hline Specific Heat & $910 \mathrm{~J} / \mathrm{Kg} \mathrm{0C}$ \\
\hline
\end{tabular}

These Aluminium (Pure) Paramaters are taken from the source [32].

Table 1.2: Material Properties of Al-SiC-Graphite [30]

\begin{tabular}{|l|c|}
\hline Young's Modulus & $7.4 \mathrm{e}+10 \mathrm{~Pa}$ \\
\hline Poisson's Ratio & 0.34 \\
\hline Impact Strength & $87 \mathrm{~J}$ \\
\hline Percentage of elongation & 7.5 \\
\hline Density & $2711.4 \mathrm{Kg} / \mathrm{m} 3$ \\
\hline Tensile Strength & $193.38 \mathrm{MPa}$ \\
\hline BHN & 68 \\
\hline Thermal Conductivity & $180 \mathrm{~W} / \mathrm{m} \mathrm{0} \mathrm{C}$ \\
\hline Specific Heat & $826 \mathrm{~J} / \mathrm{Kg} \mathrm{0} \mathrm{C}$ \\
\hline
\end{tabular}

The martial structure for hybrid metal lattice is in presence of silicon carbide $(50 \mathrm{~g})$ and graphite (30g). The hardness test report shows the hardness of the metal grid material increment by including the $\mathrm{SiC}$ and graphite, by expanding the hardness of the composite specimen and reduction of deformation. The Brunel hardness number is better in the Al-Sic-Graphite test contrasted with the unadulterated aluminum. The impact strength has been increased by including the graphite in the metal grid. Quality gets degraded with increment of graphite in excess of 30 grams. In this metal framework level of extension diminishes with addition of graphite. Elasticity has been incremented by including the SiC and graphite in composite material. The Young's modulus estimation of the hybrid metal matrix is higher contrasted with the aluminum. This exhibits that Al-SiC-Graphite is better in every way when contrasted with the unadulterated Aluminum.

\section{EFFECT OF GRAPHITE CONTENT}

Some influential parameters which play an important role during determing the wear resistance properties of composites consists of properties of the metal matrix composite, reinforcement's volume fraction as well as testing conditions applied.Graphite plays crucialcharacter in reinforcing particles in the matrix of Aluminium composition. Such matrix which consists of graphite particles in Aluminium compositescan produce such light weighted component which can be used in areas of contact wearing under differnt motions. Resistance to seizure is also improved in such cases [32, 33].

The influence of graphite content was examined by S. Mahdavi and F. Akhlaghion of slide wearing properties of Al6061/Gr hybrids along with Al6061/30SiC/Gr using a pin-on-disc wear test. The results showed that there was a reduction in porosity, friction coefficient and hardness in both the composite types when their is an increase in graphite content. Increase in porsity alongwith exhibition of high hardness character and lower coefficient of friction was exhibited by the hybrid composites with similar amount of graphite[34]. Although wearing is increasesd if more graphite is added [35]. 


\section{EFFECT OF PARTICLE SIZE OF SiC}

It has been found that a combination of particles and small fibres alongwith Hybrid metal matrix composites has been more effecient than those non hybrid metal matrix composites i.e. composites consisting of only one material as modulus and tensile strenght of metal matrix composite is increased in the case of small fibre type, while wear resistance is improved in the case of particle type combination. Further these combined metal matrix composites are modified accordingly by using specific proportions of ceramic reinforcements. These combinations have also been taken into consideration as an alternative to the widely usedwhisker reinforced or high-cost small fibres products [36]. It is to be noted that composites which has SiC particles of greater size has an upper hand as compared to those which has smaller sized particles in terms of their wear resistance properties [37].

\section{CONCLUSIONS}

- Conventional materials which has been used in automobile components are easily replacable with hybrid composite with hardness factor and better performance for longer period of life.

- Hybrid composites reinforced with aluminium alloy matrix are easily casted. And againby adding of reinforcements of hybrid nature, various characteristics such as corrosive resistance, wear resistance, toughness and hardness can further be optimised.

- It has been found out that in applications where wearing is caused severly by moving parts such as in various components of automobile engines these metal matrix composites of SiC contents of greater size are very much effecient.

- Although while comparing the rise in temperature for hybrid composite and binary composite, it has been found to be higher in hybrid ones but at the same time it is comparativelyless as in the case of composites based on iron.

- While comparing the coefficient of friction and wear rates of hybrid composites, matix alloy and individual composites, the hybrid ones has shown less waear rates as compared to the other two.

\section{FUNDING}

This study has not been funded by any individual or company.

\section{CONFLICT OF INTEREST}

The authors assure that they have no conflict of interest.

\section{REFERENCES}

1. David Weiss Eck Industries, Inc., Design of Aluminum Metal Matrix Components for Casting, 2005-01-1689., SAE TECHNICAL PAPER SERIES.

2. Ashok Kr. Mishra, Rakesh Sheokand, Intl Journal of Sci \& Research Publications, Vol 2, 10, Oct 2012.

3. Y.Wu, H.Liu and E.J.Lavernia, Scripta Metallurgica et Materiallia,1993, 41 - 61.

4. K B, Sai Sanjana, and Srikanth DV. "Thermal Analysis of Advanced IC Engine Cylinder." International Journal of Automobile Engineering Research and Development (IJAuERD) ISSN (P) (2016): 2277-4785.

5. J.JenixRino,D.Chandramohan, (IJSR), India Online ISSN: 2319-7064. 
6. D.J.Lloyd, Comp.Sci, and Tech., 35, 1989, pp.159-179.

7. M.K.Surappa and P.K.Rohatgi, Journal of Material Science. 16, 1981, pp 982-993.

8. P.S.Robi et.al, Mater.Chact., 27, 1991, pp. 11- 18.

9. Umesh, K. S., V. K. Pravin, and K. Rajagopal. "Experimental Investigation and CFD Analysis of Multi-Cylinder Four Stroke SI Engine Exhaust Manifold for Optimal Geometry to Reduce Back Pressure and to Improve Fuel Efficiency." International Journal of Automobile Engineering Research and Development, 4, 1320 (2014).

10. Karl Ulrich Kainer, Metal Matrix Composites. Custom-made Materials for Automotive and Aerospace Engineering, ISBN: 3527-31360-5.

11. S. K. Jo, W. J. Lee, Y. H. Park, I. M. Park, Tribol Lett (2012) 45:101-107.

12. S.Das and S.V.Prasad, Wear, 133, 1989, pp 173-187.

13. Bhaskar, K., et al. "Effect of dimethoxy-methane (C3H8O2) additive on emission characteristics of a diesel engine fueled with biodiesel." International Journal of Mechanical and Production Engineering Research and Development 8.1 (2018): $399-406$.

14. B.P.Krishnan, M.K.Surappa and P.K.Rohtagi, JMS., 16, 1981, 1209-1216.

15. S.Basavarajappa, G.Chandramohan, ISRS on Materials and Engineering December 20- 22, 2004.

16. Shyam Bahadur, Fundamentals of Friction and Wear.

17. S.Das et al., Mater.Trans., JIM, 32 (2), 1991, pp.189-194.

18. T.P.Murali, M.K.Surappa and P.K.Rohatgi, Metall. Trans., 13B, 1992, pp 485-494.

19. K. U. Kainer (Ed.), Metallische Verbundwerkstoffe, DGM Informationsgesellschaft, Oberursel (1994).

20. W.Henning, E. Köhler, Maschinenmarkt 1995, 101, 50-55.

21. Shivaji, Kailash B. Anwar, and S. Gowreesh. "Experimental Investigation on Use of Preheated Pongamia Oil Bio-Diesel in DI Diesel Engine." International Journal of Automobile Engineering Research and Development (IJAuERD) 4.6 (2014): 1-6.

22. S. Mielke, N. Seitz, Grosche, Int. Conf. on Metal Matrix Composites, The Institute of Metals, London (1987), pp. 4/1-4/3.

23. H. P. Degischer, Schmelzmetallurgische Herstellung von Metallmatrix-Verbundwerkstoffen, in Metallische Verbundwerkstoffe, K.U.Kainer (Ed.), DGM Informationsgesellschaft, Oberursel (1994), pp.139-168.

24. Lanxide Electronic Components, Lanxide Electronic Components, Inc., Newark USA (1995).

25. C. Fritze, Infiltration keramischer Faserformkörper mit Hilfe des Verfahrens des selbstgenerierenden Vakuums, Dissertation TU Clausthal (1997).

26. Duralcan Composites for Gravity Castings, Duralcan USA, San Diego (1992).

27. Duralcan Composites for High-Pressure Die Castings, Duralcan USA, San Diego (1992).

28. C. W. Brown, W.Harrigan, J. F. Dolowy, Proc. Verbundwerk 90, Demat, Frankfurt (1990), pp. 20.1-20.15.

29. Manufacturers of Discontinuously Reinforced Aluminum (DRA), DWA Composite Specialities, Inc., Chatsworth USA (1995).

30. A. G. Leatham, A. Ogilvy, L. Elias, Proc. Int. Conf. P/M in Aerospace, Defence and Demanding Applications, MPIF, Princeton, USA (1993), pp. 165-175.

31. Cospray Ltd. Banbury, U.K., 1992. 
32. Keramal Aluminum-Verbundwerkstoffe, Aluminum Ranshofen Ges.m.b.H., Ranshofen, Österreich (1992).

33. F. Koopmann, Kontrolle Heft 1/2 (1996), pp. 40-44.

34. Nunna Durga Prasanth* , Dr.B Venkataraman, Experimental investigation and analysis of piston by using hybrid metal matrix, IJESRT, ISSN: 2277-9655, 2015.

35. Er. Rachit Marwaha, Mr. Rahul Dev Gupta, Er. Krishan Kant Sharma "Determination \& Experimental Investigation Of Weight Loss On Al/Sic/Gr - Metal Matrix Hybrid Composite By Taguchi Method”Volume 2, Issue 11, November 2013.

36. R. Ravi Raja Malarvannan and P. Vignesh "Experimental Investigation and Analysis of Piston by using Composite Materials" Vol 04, Article-K100; November 2013.

37. Joel Hemanth, Trans. AFS, 5, 1999, 769.

38. G. B. Veeresh Kumar, C. S. P. Rao, N. Selvaraj, JMMCE, Vol. 10, pp.59-91, 2011.

39. Harish K.Garg Intl Journal of Latest Research in Science and Technology Vol.1, Issue 1 :36-44,May-June(2012).

40. Haizhi Ye, ASM Int JMEPEG (2003) 12:288-297.

41. V.C.Uvaraja, International Journal of Engineering Technology Volume 2, 2012. 